\title{
Experimental Characterisation of the Bainitic Transformation Kinetics of Residual Austenite in Mn-Si TRIP-Assisted Multiphase Steels
}

\author{
P. Jacques, E. Girault*, J. van Humbeeck*, E. Aernoudt* and F. Delannay \\ Université Catholique de Louvain, Département des Sciences des Matériaux et des Procédés, PCIM, \\ Place Sainte Barbe 2, 1348 Louvain-la-Neuve, Belgium \\ * Department of Metallurgy and Materials Engineering, K.U. Leuven, de Croylaan 2, 3001 Leuven, \\ Belgium
}

\begin{abstract}
Recent studies on TRIP-assisted multiphase steels have emphasised the drastic importance of the bainitic transformation in the optimisation of properties. Bainitic ageing is necessary for the stabilisation of austenite with respect to the martensitic transformation. This metastable retained austenite can still transform to martensite when plastically deformed (TRIP effect). The present work deals with the bainitic reaction kinetics of the austenite obtained by intercritical annealing in two low carbon $\mathrm{Mn}-\mathrm{Si}$ steels. Bainitic transformation was followed by dilatometry and SEM observations. X-ray diffraction and Mössbauer spectrometry allowed the measurement of the amount of residual austenite and of the carbon enrichment in austenite. The tempering temperature was found to influence the kinetics of austenite transformation and decomposition.
\end{abstract}

\section{INTRODUCTION}

The control of the bainitic transformation is of primary importance in tuning of the mechanical properties of steels. A recent example is the development of TRIP-assisted multiphase steels for which bainitic tempering plays a prominent role [1]. TRIP-aided steels usually present rather high silicon and manganese contents (from 1 to $2.5 \mathrm{wt} . \%$ ). The influence of these two elements on the bainitic transformation kinetics has been thoroughly studied because of their common use. Nevertheless, a clear understanding seems not to be established when both elements are simultaneously present in the same alloy as in TRIP-assisted steels. Some studies have shown that the effects of $\mathrm{Si}$ and $\mathrm{Mn}$ on bainitic reaction kinetics are not simply additive [2]. Furthermore, Si and Mn seem to have opposite influences on the so-called incomplete bainitic reaction phenomenon and on the later decomposition of residual austenite. This study aims at contributing to the understanding of the bainitic transformation kinetics taking place during the tempering of a TRIP-aided steel. The influence of the bainitic ageing temperature on austenite stabilisation and on the subsequent decomposition of austenite is also experimentally demonstrated.

\section{EXPERIMENTAL PROCEDURES}

The compositions of the two steels investigated in this work are shown in Table 1. Both alloys were hot and cold-rolled down to thicknesses between 0.8 and $1.0 \mathrm{~mm}$ following standard procedures.

Table 1 : Chemical compositions (wt.\%) of the studied steels.

\begin{tabular}{cccccccc}
\hline Steel & $\mathbf{C}$ & $\mathbf{S i}$ & $\mathbf{M n}$ & $\mathbf{P}$ & $\mathbf{S}$ & Sol. Al & $\mathbf{N}$ \\
\hline A & 0.11 & 1.50 & 1.53 & 0.008 & 0.006 & 0.043 & 0.0035 \\
\hline B & 0.18 & 0.39 & 1.30 & 0.020 & 0.010 & 0.029 & 0.0070 \\
\hline
\end{tabular}


Figure 1 displays the thermal scheme applied on the cold-rolled sheets in order to obtain the desired multiphase microstructure. The material is first annealed at an intercritical temperature where austenite and ferrite coexist. It is then steeply cooled and held at an intermediate ageing temperature where the bainitic reaction takes place which contributes to the stabilisation of the residual austenite. The cycle is completed by a final cooling to room temperature. The thermal treatment of steel A was simulated in a Theta dilatometer using $15 \times 4 \times 0.8 \mathrm{~mm}$ flat specimens cut out by spark-erosion. Heating was achieved by induction whereas fast cooling was performed by means of a high pressure helium spray. Experiments were carried out under vacuum to restrict decarburisation of the samples during annealing. The length change of the dilatometer specimens was continuously monitored during the ageing stage to study the kinetics of bainite formation. For steel B, intercritical annealing was conducted in a fluidised bed furnace. The samples were then transferred in a lead bath furnace for bainitic tempering.

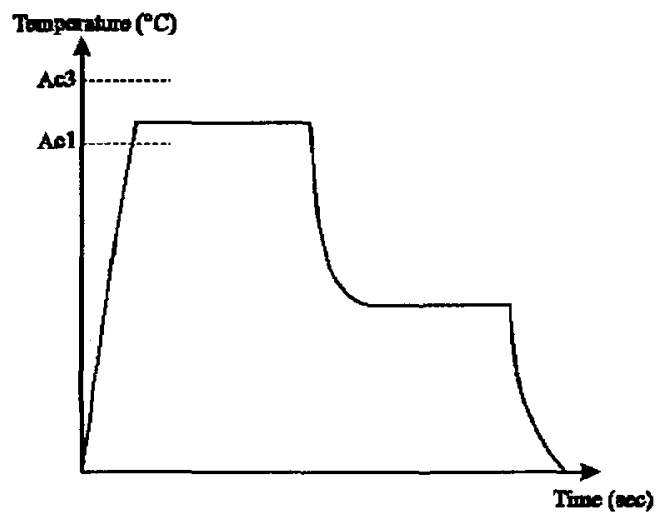

Figure 1 : TRIP heat treatment performed on the as cold-rolled sheets.

Microstructural study was done on samples interruptedly quenched during the thermal cycle. As presented elsewhere [3], a particular sample preparation was carried out prior to SEM observations. The amount of retained austenite on steel $\mathrm{A}$ was measured by $\mathrm{X}$-ray diffraction from the integrated intensities of diffraction peaks (200) $\gamma,(220) \gamma,(311) \gamma,(200) \alpha,(211) \alpha$, and (220) $\alpha$ using $\mathrm{Cu} \mathrm{K} \alpha$ radiation [4]. The carbon content of retained austenite was estimated from the lattice parameter $\mathrm{a}_{0}$ measured from the $(220) \gamma$ peak using the relationship $\mathrm{a}_{0}(\AA)=3.573+0.033(\mathrm{wt} . \% \mathrm{C})$ [5]. The effect of the manganese and silicon content on $a_{0}$ was neglected with respect to that of the carbon content $[6,7]$. Retained austenite content of steel B was determined by Mössbauer spectroscopy. The samples were first chemically and then electrolytically thinned to a thickness of $100 \mu \mathrm{m}$.

\section{RESULTS AND DISCUSSION}

Steel A intercritical annealing consisted in soaking at a temperature of $750^{\circ} \mathrm{C}$ for 4 minutes. The samples were subsequently cooled to the ageing temperature at a rate between 75 and $100^{\circ} \mathrm{C} / \mathrm{s}$. The change with time of the volume fraction transformed to bainite was studied at 375,416 and $450^{\circ} \mathrm{C}$. It is presented in figure 2 . 
Absolute values were measured by calibration of the elongation curve obtained by dilatometry. The normalisation was performed by identifying the values at the ends with the values derived from image analyses and XRD measurements. It is remarkable that the curves in figure 2 exhibit the incomplete reaction phenomenon generally attributed to $\mathrm{Si}$ bearing steels. The results show a strong dependence of the bainitic transformation kinetics with the holding temperature, a rise of the latter leading to accelerated transformation rates. This result denotes the existence of a diffusional mechanism for the bainitic reaction within the studied temperature range. This mechanism can be attributed to a thermally activated carbon partitioning that occurs during the progress of the transformation [8]. The degree of transformation to bainite seems not to be much sensitive to the transformation temperature, even if a small increase is noticeable as the temperature is reduced. This trend is in agreement with the displacive feature of the bainitic reaction, which predicts a larger rate at lower temperatures [9]. The continuity of the ultimate transformation rates support the assumption that all ageing treatments are conducted within the upper bainite transformation field. For this transformation regime, the resulting kinetics curves express the combined action of diffusive and displacive phenomena.

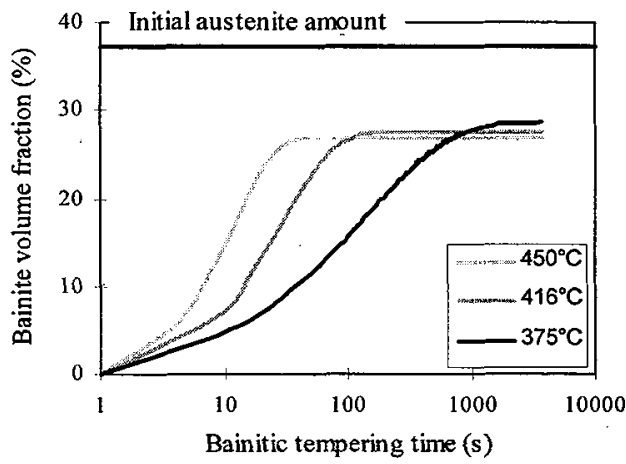

Figure 2 : Kinetics of the bainitic reaction with respect to the holding temperature.

Figure 3 presents the change of the volume fraction and the carbon content of retained austenite as a function of the bainitic tempering time at $450^{\circ} \mathrm{C}$. These curves are to be compared with the corresponding dilatometric plots of figure 2 . Ageing can be divided in two different stages. The first stage corresponds to the carbon enrichment of the residual austenite coupled with the formation of bainite. This enrichment increases the austenite stability which is expressed in the retained austenite content measured at room temperature. The second stage is characterised by combined decrease of the austenite volume fraction and carbon content, attributed to the decomposition of the residual austenite [10]. This decomposition is clearly observable by SEM, as shown in figure 4 . Other tests showed the attainment of a higher carbon enrichment with decreasing temperature. Besides, the drop of the carbon content of the residual austenite is detected to a lesser extent at longer times when the ageing temperature decreases. It can be concluded that the limitation of the carbon enrichment at high temperatures is due to a competition between the bainitic transformation and the austenite decomposition. 


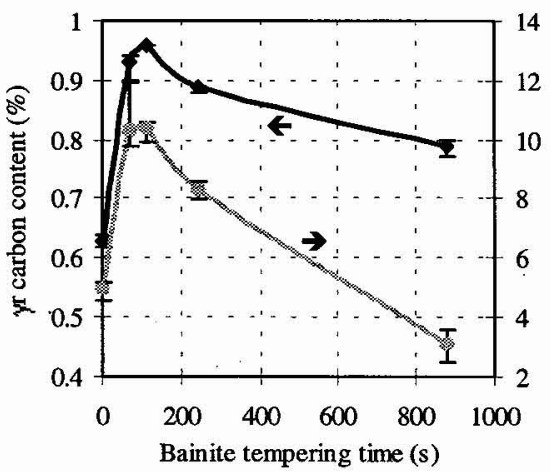

Figure 3 : Retained austenite stabilisation and decomposition during bainitic tempering at $450^{\circ} \mathrm{C}$.

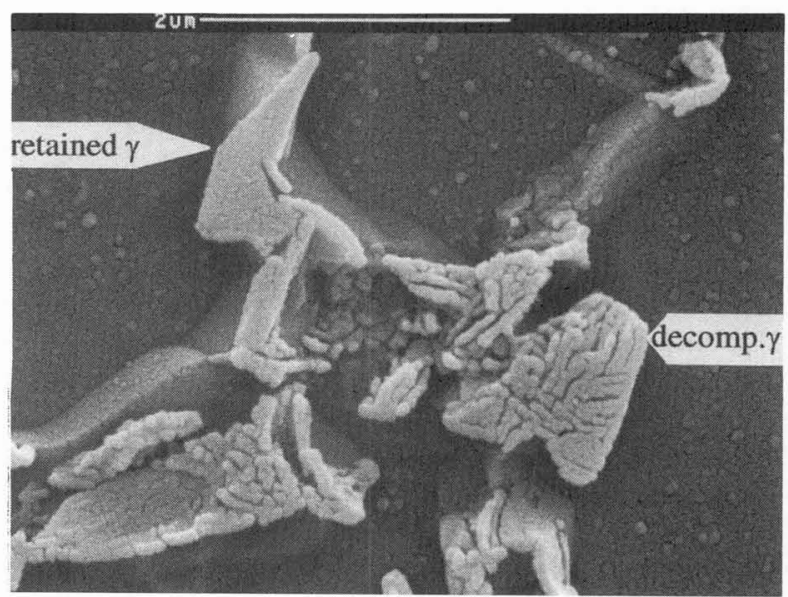

Figure 4 : SEM micrograph of steel A aged for $15 \mathrm{~min}$. Retained austenite (smooth) and decomposed austenite (cracked) are both visible.

Samples of steel B were intercritically annealed at $730^{\circ} \mathrm{C}$ for 5 minutes followed by tempering at $430^{\circ} \mathrm{C}$ for different times. Figure 5 shows a typical microstructure after a tempering time of 1 minute. Bainite and retained austenite are dispersed within the ferritic matrix. No more martensite can be observed after this holding time. Furthermore, it can be seen on figure 6 that austenite decomposition starts to be detectable for a tempering time of 3 minutes. Comparison of these results with figure 3 indicates that steels $A$ and $B$ exhibit about the same bainitic transformation kinetics despite major differences in silicon content. Nevertheless, the Si content is found to influence much the incomplete reaction phenomenon [2]. In spite of a carbon content 1.5 times larger for steel B than for steel A, the maximum amount of retained austenite is only $5 \%$ compared to $11 \%$ for steel A. Austenite decomposition kinetics is also faster [11]: after a tempering time of 10 minutes, only $0.6 \%$ of austenite remains in the microstructure.

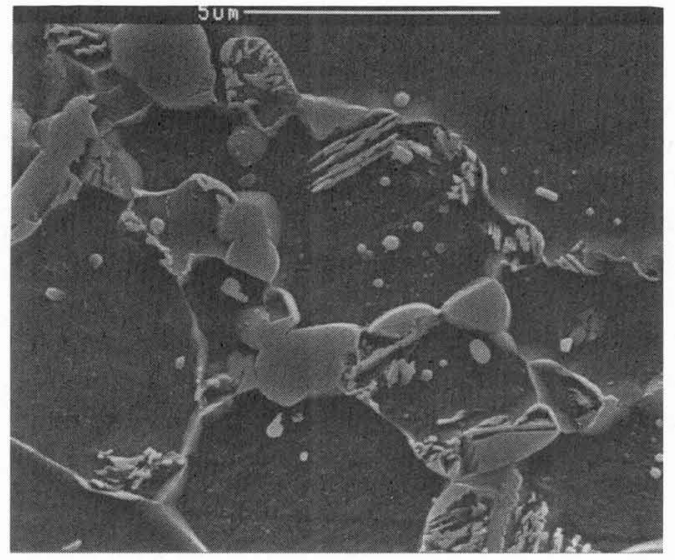

Figure 5 : Microstructure of steel B after $1 \mathrm{~min}$ tempering. No more martensite is present, the second phase being composed of bainite and retained austenite.

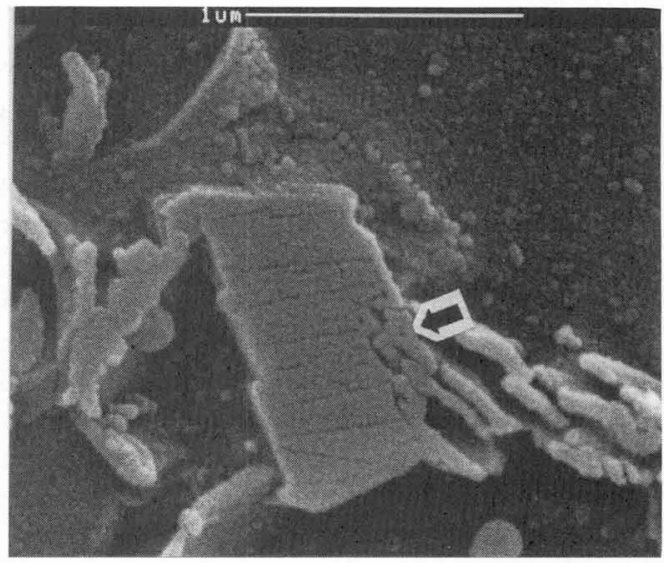

Figure 6 : Slight austenite decomposition observed on steel $B$ aged for $3 \mathrm{~min}$. 


\section{CONCLUSION}

This study presents the characterisation of the bainitic ageing kinetics of a TRIP-aided annealing treatment. Two alloy compositions were investigated and some common trends can be drawn. Faster transformation kinetics have been observed at higher tempering temperatures. The associated maximum carbon enrichment was found to be temperature dependent, which was mainly attributed to the emergence of austenite decomposition. The extent of this austenite decomposition was larger in the low silicon steel which confirmed the carbide precipitation inhibition induced by this element.

\section{Acknowledgements}

The authors are indebted to OCAS (Research Centre of the Sidmar Group) and RDCS (R\&D Centre of the Cockerill-Sambre group) for continuous support and collaboration. The authors are grateful to Dr. J. Ladrière for Mössbauer measurements. This research was carried out under financial support of the Flemish Institute of the Scientific Technological Research in the Industry (IWT) and the Walloon Region (FIRST programme $n^{\circ} 3129$ ). This research was partly supported by the Belgian State, Prime Minister's Office, Federal Office for Scientific, Technical and Cultural Affairs, under contract P4/33 Interuniversity Poles of Attraction Programme. Jan Van Humbeeck acknowledges the FWO (Fonds voor Wetenschappelijk Onderzoek).

\section{References}

[1] O. Matsumura, Y. Sakuma, H. Takeshi, Trans. ISIJ 27 (1987), 570-579.

[2] S. K. Liu, J. Zhang, Metall. Trans. A 21 (1990), 1517-1525.

[3] E. Girault, P. Jacques, Ph. Harlet, K. Mols, J. Van Humbeeck, E. Aernoudt, F. Delannay, submitted to Mater. Charact.

[4] C. F. Jatczak, J. A. Larson, and S. W. Shin, Society of Automotive Engineers, Inc (1980).

[5] N. Ridley, H. Stuart, and L. Zwell, Trans. TMS-AIME 245 (1969), 1834-1836.

[6] R. C. Ruhl, and M. Cohen, Trans. TMS-AIME 245 (1969), 241-251.

[7] K. J. Irvine, D. T. Llewellyn and F. B. Pickering, J. Iron Steel Inst. 199 (1961), 153-175.

[8] C. Zener, Trans. AIME 167 (1946), 550.

[9] H. K. D. H. Bhadeshia, Bainite in Steels (Institute of Materials, London, 1992), 124-195.

[10] H. K. D. H. Bhadeshia, ibid., 94-98.

[11] H. K. D. H. Bhadeshia, ibid., 72-74. 